\title{
Do carotid bruits predict disease of the internal carotid arteries?
}

\author{
Keren N. Davies and Peter R.D. Humphrey
}

The Walton Centre for Neurology and Neurosurgery, Rice Lane, Liverpool L9 1AE, UK

\begin{abstract}
Summary: A carotid bruit is often thought of as a reliable sign of extracranial carotid artery disease. In addition finding a bruit may precipitate a referral to hospital. Carotid endarterectomy has now been shown to be beneficial in patients with symptomatic carotid territory ischaemia and 70-99\% stenosis of the relevant carotid artery, therefore it is important that such patients are detected and referred.

In this study of $\mathbf{3 3 1}$ consecutive patients referred to a specialist cerebrovascular clinic we examined the practical value of a carotid bruit mentioned by the referring practitioner. All patients underwent clinical assessment, evaluation of risk factors and Doppler duplex scanning of the carotid arteries. $A$ bruit was stated in the referral letter of $110(33 \%)$ patients. Moderate (30-69\%) or severe (70-99\%) stenosis was present in $37 \%$ of patients with, and $17 \%$ of those without a carotid bruit $(P<0.001)$. We found a carotid bruit was a poor predictor of such disease (positive predictive value, $37 \%$ ). The false negative rate for severe disease was $43 \%$. Normal carotid arteries were found in $32 \%$ of patients with a bruit. We therefore suggest that all patients with suspected carotid territory ischaemia should be referred for assessment whether there is a bruit present or not.
\end{abstract}

\section{Introduction}

Carotid endarterectomy has been shown to benefit patients with symptomatic cerebral ischaemia and greater than $70 \%$ stenosis of the relevant carotid artery. ${ }^{1,2}$ The European Carotid Surgery trial ${ }^{2}$ also reported that patients with mild $(0-29 \%)$ stenosis did not benefit from surgery, while the results for those with moderate stenosis (30-69\%) are awaited. The detection of internal carotid artery (ICA) disease in patients with symptomatic carotid territory ischaemia is, therefore, of importance.

Fisher ${ }^{3}$ described the association of a carotid bruit and cerebrovascular disease in 1957. In 1980 Barnes $^{4}$ concluded that bruits were the most common sign of extracranial carotid artery disease and that they rarely occurred in the absence of carotid artery disease. This conclusion has subsequently been challenged ${ }^{5,6}$ and we therefore decided to examine the practical value of a carotid bruit. We looked at the predictive value of a carotid bruit as mentioned in the referral letter, both for carotid territory symptoms and/or disease of the internal carotid artery. The presence of such a bruit is likely to precipitate a referral.

Correspondence: K. Davies, M.Sc., M.R.C.P.(UK)., Department of Health Care for the Elderly, The Royal London Hospital Mile End, Bancroft Road, London E1 4DG, UK.

Accepted: 26 January 1994

\section{Subjects and methods}

Three hundred and thirty-one consecutive patients referred to a specialist cerebrovascular clinic were assessed. A carotid bruit was stated in the referral letter in $110(33 \%)$ patients, (56 (51\%) male, median age 63 years, range $28-80$ years) of whom 36 had bilateral bruits. The other 221 patients (126 male $(57 \%)$, median age 60 , range $18-87$ years) had been referred for assessment of possible carotid territory symptoms but did not have a carotid bruit. All patients underwent clinical assessment, screening for vascular risk factors and Doppler duplex scanning (Kranzbuhler Doppler 761, $4 \mathrm{mHz}$ and $8 \mathrm{mHz}$ transducers, Diasonics CV 400, $10 \mathrm{mHz}$ transducer) of the internal carotid arteries.

\section{Statistical methods}

Data are described as median (range). Statistical analysis was performed with chi-square test with Yates correction where appropriate. A $P$ value of 0.05 was considered significant.

\section{Results}

Forty-five ( $41 \%$ ) of the 110 patients referred with a bruit had symptoms of carotid territory disease 
compared to $149 / 221(67 \%)$ of the group without a bruit $\left(\chi^{2}=21.28, P<0.001\right)$. The positive predictive value of a bruit for patients with carotid symptoms was $41 \%$ (sensitivity $23 \%$, specificity $53 \%)$.

The presenting symptoms for the two groups (those referred with a bruit versus those without) are shown in Table I. There was a significant difference in the presenting complaints for those with carotid symptoms. There was a higher frequency of stroke and lower frequency of transient ischaemic attack (TIA) in those without a bruit $\left(\chi^{2}=5.3\right.$, d.f. $\left.=3, P=0.02\right)$. The findings on Doppler duplex scanning are shown in Table II. The findings were abnormal in $75 / 110(68 \%)$ with a bruit versus $134 / 221(61 \%)$ (NS). The positive predictive value of a bruit for any disease of the ICA was $68 \%$ (sensitivity $36 \%$, specificity $71 \%$ ).

Moderate or severe ICA disease was present in $41 / 110(37 \%)$ with a bruit and $37 / 221(17 \%)$ without a bruit $\left(\chi^{2}=17.2\right.$, d.f. $\left.=3, P<0.001\right)$. The positive predictive value of a bruit for moderate or severe ICA disease was $37 \%$ (sensitivity $53 \%$, specificity $73 \%$ ). The false negative rate (the percentage of patients with stenosed arteries and no bruit) was $47 \%$. For severe disease (70-99\%

Table I Presenting symptoms on referral to cerebrovascular clinic

\begin{tabular}{lcc}
\hline ICA symptoms & $\begin{array}{c}\text { Bruit present } \\
(\mathrm{n}=110)\end{array}$ & $\begin{array}{c}\text { No bruit } \\
(\mathrm{n}=221)\end{array}$ \\
\hline None & $65(59 \%)$ & $72(32 \%)$ \\
TIA (eye/brain) & $28(25 \%)$ & $63(29 \%)$ \\
Stroke & $15(14 \%)$ & $77(35 \%)$ \\
CRAO & $2(2 \%)$ & $9(4 \%)$ \\
\hline
\end{tabular}

ICA $=$ internal carotid artery; TIA = transient ischaemic attack; $\mathrm{CRAO}=$ central retinal artery occlusion.

Table II Doppler duplex scan results all patients. Findings described on side of bruit or symptomatic side in those without a bruit

\begin{tabular}{lcc}
\hline Doppler/duplex result ICA & $\begin{array}{c}\text { Bruit present } \\
(\mathrm{n}=110)\end{array}$ & $\begin{array}{c}\text { No bruit } \\
(\mathrm{n}=221)\end{array}$ \\
\hline $\begin{array}{l}\text { Normal } \\
\text { Atheroma/mild stenosis }\end{array}$ & $35(32 \%)$ & $87(39 \%)$ \\
$\quad(<30 \%)$ & $27(25 \%)$ & $72(33 \%)$ \\
$\begin{array}{l}\text { Moderate stenosis } \\
(30-69 \%)\end{array}$ & $17(15 \%)$ & $19(9 \%)$ \\
$\begin{array}{l}\text { Severe stenosis (70-99\%) } \\
\begin{array}{l}\text { Occlusion } \\
\text { Reduced flow/syphon } \\
\text { disease }\end{array}\end{array}$ & $24(22 \%)$ & $18(8 \%)$ \\
\hline
\end{tabular}

ICA = internal carotid artery. stenosis) only, the sensitivity was $57 \%$, the $\bar{z}$ specificity $70 \%$ and the false negative rate $43 \%$.

In patients with moderate or severe disease, $\subseteq$ $41 / 78(53 \%)$ had a bruit; $35(85 \%)$ of these patients $\overrightarrow{\overrightarrow{\mathrm{F}}}$ were 55 years or over. The positive predictive value of a bruit for any disease of the ICA was $48 \%$ for patients less than 55 years $(n=96)$ but increased to $\frac{\bar{\omega}}{\bar{\omega}}$ $75 \%$ for patients 55 years and over. In those $\frac{\widetilde{\sigma}}{\sigma}$ patients with normal findings on Doppler duplex scan $35 / 122(29 \%)$ had a bruit.

\section{Discussion}

The importance of a carotid bruit in predicting atherosclerosis of the ICAs has been disputed for more than 30 years, long before the value of carotid 0 endarterectomy was confirmed. ${ }^{1,2}$ Early reports $\stackrel{\infty}{\sim}$ showed the value of a carotid bruit in patients with symptomatic carotid territory ischaemia ${ }^{7,8}$ but $\underset{\omega}{\omega}$ Hennerici et al. ${ }^{5}$ and Lusiani et al.$^{6}$ found the sign to 0 be insufficiently specific. The two most recent large studies ${ }^{9,10}$ have suggested that in selected popula- $\vec{C}$ tions the presence of a carotid bruit increases the likelihood of finding disease of the extracranial carotid arteries, but not necessarily severe stenosis. Both of these studies depended on cerebral angio- ? graphy to confirm disease.

Doppler duplex scanning in experienced hands is as accurate as this invasive technique and is currently preferred for screening purposes. ${ }^{11}$ In this study of unselected patients referred to our clinic, all of whom had Doppler duplex studies, a carotid bruit was a poor predictor for moderate or severe ICA disease, furthermore, even in those patients with symptoms compatible with carotid territory disease, the predictive value was only $41 \%$. A bruit appears to be a better marker for any ICA disease (including atheroma or mild stenosis) which concurs with the findings of other authors. ${ }^{9,12}$ The finding of localized asymptomatic carotid arterial bruits increases with age; ${ }^{13}$ we have shown that a carotid bruit is of greater predictive value in those over 55 years.

Ingall et al. ${ }^{9}$ reviewed previous studies and suggested a predictive value of carotid bruit for moderate to severe ICA disease varying between 51 to $90 \%$. Most of the studies reviewed were of $N$ selected patient groups undergoing expert evalua- N tion of the arterial bruits and having cerebral angiography for diagnosis. In comparison our study was in an unselected group of patients and carotid bruits were noted by the referring doctors. This may explain the discrepancy in the value of a carotid bruit between this and other studies ${ }^{9}$ but is likely to be of greater practical relevance. Ingall et al. ${ }^{9}$ also showed that only $3 \%$ of patients with a bruit had normal vessels, whereas we found normal vessels in $33 \%$. Hankey and Warlow ${ }^{10}$ found that if 
only patients with a carotid bruit were investigated by angiography, $20 \%$ with more than $50 \%$ stenosis and $9 \%$ of patients with greater than $75 \%$ stenosis would be denied investigation and hence the possibility of treatment. Our finding of a false negative rate of $56 \%$ for severe stenosis agrees with these findings.

In conclusion, the finding of severe atheroma-

\section{References}

1. North American Symptomatic Carotid Endarterectomy Trial Collaborators. Beneficial effect of carotid endarterectomy in symptomatic patients with high grade stenosis. $N$ Engl J Med 1991, 325: 445-453.

2. European Carotid Surgery Triallists Collaborative group. MRC European Carotid surgery trial; interim results for symptomatic patients with severe $(70-99 \%)$ or with mild (0-29\%) carotid stenosis. Lancet 1991, 337: 1235-1243.

3. Fisher, C.M. Cranial bruit associated with occlusion of the internal carotid artery. Neurology 1957, 7: 299-306.

4. Barnes, R. Noninvasive evaluation of the carotid bruit. Annu Rev Med 1980, 31: 201-218.

5. Hennerici, M., Aulich, A., Sandmann, W. \& Freund, H.J. Incidence of asymptomatic extracranial arterial disease. Stroke 1981, 12: 750-758.

6. Lusiani, L., Visona, A., Castellani, V., Ronsisvalle, G., Bononome, A. \& Pagnan, A. Prevalence of atherosclerotic lesions at the carotid bifurcation in patients with asymptomatic bruits: an echo-Doppler (duplex) study. Angiology 1985, 36: 235-239.

7. Harrison, M.J.G. \& Marshall, J. Indications for angiography and surgery in carotid artery disease. Br Med J 1975, 1: 616-617. tous disease in patients without a bruit and the poor predictive value of a bruit for moderate or severe disease means that all patients with suspected carotid territory ischaemia should be referred for assessment whether there is a carotid bruit present or not and particularly older patients. Referring only patients with a bruit will result in many being deprived of a treatment of proven value.

8. Wilson, I.A. \& Ross-Russell, R.W. Amaurosis fugax and carotid artery disease: indications for angiography. $\mathrm{Br} \mathrm{Med} J$ 1977, 2: 435-437.

9. Ingall, T.J., Homer, D., Whisnant, J.P., Baker, H.L. \& O'Fallon, W.M. Predictive value of carotid bruit for carotid atherosclerosis. Arch Neurol 1989, 46: 418-422.

10. Hankey, G.J. \& Warlow, C. Symptomatic carotid ischaemic events: safest and most cost effective way of selecting patients for angiography, before carotid endarterectomy. $\mathrm{Br}$ Med $J$ 1990, 33: 1485-1491.

11. Humphrey, P., Sandercock, P. \& Slattery, J.A. Simple method to improve the accuracy of non-invasive ultrasound in selecting TIA patients for cerebral angiography. $J$ Neurol Neurosurg Psychiatry 1990, 53: 966-971.

12. Pessin, M.S., Panis, W., Prager, R.J., Millan, V.G. \& Scott, R.M. Auscultation of cervical and ocular bruits in extracranial carotid occlusive disease: a clinical and angiographic study. Stroke 1983, 14: 246-249.

13. Sandok, B.A., Whisnant, J.P., Furlan, A.J. \& Mickell, J.L. Carotid artery bruits. Prevalence survey and differential diagnosis. Mayo Clin Proc 1982, 57: 227-230. 